RESEARCHARTICLE

\title{
Is There a Role of Hemoglobin A1C in Predicting Hospital Re- Admission Rates for Patients with Diabetes?
}

\author{
Hirva Bakeri ${ }^{1 *}$, Dorothy Wakefield ${ }^{2}$, Latha Dulipsing ${ }^{3}$ \\ 'Department of Medicine, University of Connecticut Health Center, USA \\ ${ }^{2}$ Center for Public Health and Health Policy, University of Connecticut Health Center, USA \\ ${ }^{3}$ Center for Diabetes and Metabolic Care, Saint Francis Hospital and Medical Center, USA
}

\begin{abstract}
The purpose of this study is to evaluate the role of $\mathrm{HbA} 1 \mathrm{C}$ and its impact on hospital readmission. Despite widespread recognition of the burden of hospital readmissions, there are only a few studies focused on readmissions among patients with diabetes. We hypothesize that $\mathrm{HbA1C}$ values are associated with hospital readmission rates and would be an important indicator of risk of hospital readmission.

Data were collected retrospectively on 5, 126 patients admitted to Saint Francis Hospital Medical Center (SFHMC) with either primary or secondary diagnosis of diabetes from Oct. $1^{\text {st }}$, 2014-Sept. 30, 2015.

The primary outcome in our study was that while HbA1C did not play a role in predicting 30day readmissions, patients with multiple readmissions within 30 days had a significantly higher $\mathrm{HbA} 1 \mathrm{C}$ level as compared to those with one readmission. Secondary findings in our study included: 1) patients with a primary diagnosis of diabetes had a significantly higher HbA1C than those with a secondary diagnosis, 2) patients admitted with a primary diagnosis of diabetes had a higher incidence of HbA1C testing than those admitted with a secondary diagnosis of diabetes.
\end{abstract}

Open Access

Citation: Bakeri $\mathrm{H}$, Wakefield D, The study is significant to a wider audience as it could assist in designing interventions to decrease healthcare costs related to diabetes.

Dulipsingh L. Is There a Role of Hemoglobin A1C in Predicting Hospital Readmission Rates for Patients with Diabetes? Endocrinology Diabetes and Obesity. 2018; 1(2):3.

Received: June 25, 2018

Accepted: November 19, 2018

Published: December 07, 2018

Copyright: @ 2018 Bakeri H. This is an open access article distributed under the terms of the Creative Commons Attribution License, which permits unrestricted use, distribution, and reproduction in any medium, provided the original author and source are credited.

\section{Corresponding author:}

Hirva Bakeri, Department of Medicine, University of Connecticut Health Center, USA

Email: hirvabakeri@gmail.com

\section{Keywords}

Hemoglobin $\mathrm{A} 1 \mathrm{C} ; \mathrm{HbA} 1 \mathrm{C}$; diabetes; readmission; cost effectiveness

\section{Introduction}

Hospital readmission is an indicator of quality of care and plays a significant role in total medical cost. A large proportion of hospital costs are attributed to a small percentage of patients with chronic medical conditions who have repeated hospitalizations. ${ }^{1}$ As per Jencks et al., approximately $20 \%$ of all hospitalized Medicare patients are readmitted within 30 days, and $34 \%$ are readmitted within 90 days of discharge. ${ }^{2}$ Co-morbid medical conditions that have been associated with readmission included chronic obstructive pulmonary disease (COPD), alcoholism, diabetes mellitus (DM), chronic renal failure, liver disease, anemia, acute coronary syndrome, congestive heart failure $(\mathrm{CHF})$, peripheral vascular disease, and malignancy. ${ }^{1}$

The American Diabetes Association (ADA), in 2017, estimated that the cost of diabetes was $\$ 327$ billion, with $\$ 237$ billion of this cost incurred by direct medical costs and $\$ 90$ billion in reduced productivity. ${ }^{3}$ Providing care to a patient with diabetes is estimated to cost approximately 2.3 times that of a patient without diabetes ${ }^{3}$, explained by the fact that chronically elevated blood glucose is associated with an increased risk of organ damage. Complications caused by elevated glucose levels include microvasculopathy, nephropathy, 
retinopathy, and death. ${ }^{4}$

The ADA has recommended the use of blood hemoglobin $\mathrm{A} 1 \mathrm{C}(\mathrm{HbA} 1 \mathrm{C})$ level to assess longterm glycemic control in patients with diabetes. Chronic glycemic control in the outpatient setting as well as attention to glycemic control in the hospital setting may facilitate sustained glycemic control post-discharge and reduce hospitalizations. The ADA proposes an HbA1C target of $<7 \%$ to reduce microvascular complications in non-pregnant adults. However, it further recommends that $\mathrm{HbA} 1 \mathrm{C}$ goals be individualized based on duration of diabetes, age/life expectancy, co-morbidities, hypoglycemic unawareness and individual considerations ${ }^{5}$.

Despite widespread recognition of the impact of hospital readmissions, there are only a few studies focused on readmissions among patients with diabetes, and these studies have conflicting conclusions. The aim of this study is to evaluate whether the value of $\mathrm{HbA} 1 \mathrm{C}$ or frequency of its testing has an impact on readmission rates. We hypothesize that elevated $\mathrm{HbA} 1 \mathrm{C}$ values are associated with increased hospital readmission rates and thus would be important indicators of risk of hospital admission. Such information could be used to design interventional programs to promote reduction in morbidity and cost related to diabetes and to find future directions to improve patient cost and safety.

\section{Methods}

We obtained approval from the Institutional Review Board and retrospectively collected data on patients admitted to Saint Francis Hospital Medical Center (SFHMC) with either primary or secondary diagnosis of diabetes from Oct. $1^{\text {st }}, 2014-S e p t .30^{\text {th }}, 2015$. We selected patients who had a primary or secondary diagnosis of diabetes mellitus based on the ICD-9CM codes ranging from 250-250.93. All patients admitted with a primary or secondary diagnosis of diabetes to any critical care or non-critical care unit in the hospital were included. Exclusion criteria included the following: patients below 18 years of age, and patients without the diagnosis of diabetes.

This study used information from reports created from the EPIC electronic medical record (EMR) system. All data were de-identified in compliance with the Health Insurance Portability and Accountability Act of 1996 before being provided to the investigators.

We gathered data from 5,126 patients. This data included inpatient encounter data, laboratory data (including $\mathrm{HbA} 1 \mathrm{C}$ ), the admission diagnosis, length of stay (LOS), and hospital readmission.

The primary outcome of interest was to evaluate whether $\mathrm{HbA} 1 \mathrm{C}$ correlated with 30-day readmission rates. A readmitted patient was defined as any patient being admitted to the hospital within 30 days of discharge. As mentioned previously, $\mathrm{HbA} 1 \mathrm{C}$ is a measure of glycemic control reflecting the efficacy and quality of diabetes care a patient has been receiving.

\section{Statistical Analyses}

Descriptive statistics (mean $(S D)$ or frequency $(\%)$ ) were calculated for all variables of interest. Chi-squared analyses compared the number of patients with $\mathrm{HbA1c}$ tests and the number of readmissions by primary or secondary diagnosis. $T$-tests compared the mean $\mathrm{HbA} 1 \mathrm{c}$ levels by primary or secondary diagnosis. Wilcoxon rank-sum compared the hospital length of stay by group. All analyses were repeated to compare groups with (1 or more) and without readmissions. Statistical analyses were performed with SAS version 9.4 (Cary, North Carolina). A p value $<0.05$ was considered significant.

\section{Results}

There were 7,561 admissions with a primary or secondary diagnosis of diabetes at SFHMC between October 1, 2014 and September 30, 2015 for 5,126 unique patients. Of the 7,561 admissions, 969 resulted in a total of 1,118 30-day readmissions due to multiple readmissions. The number of 30-day readmissions per patient ranged from 1 to 3 . Of the 140 patients with multiple readmissions, 131 patients had 2 readmissions and 9 patients had 3 readmissions (Table 1 ). 


\section{HbA1C testing}

$\mathrm{HbA} 1 \mathrm{C}$ testing was considered 'complete' if it was done during the hospitalization or within 60 days prior to the initial admission. Overall, 3,189 (42.2\%) of the 7,561 total admissions had a completed $\mathrm{HbA} 1 \mathrm{C}$. Of the 969 admissions with 30-day readmissions, $428(44.2 \%)$ had $\mathrm{HbA} 1 \mathrm{C}$ testing completed. The proportion with $\mathrm{HbA} 1 \mathrm{c}$ tests among the 6,592 admissions without readmissions $(41.9 \%)$ was similar $(p=0.18)$. Among those who had a complete $\mathrm{HbA} 1 \mathrm{C}$, there was no difference in the average $\mathrm{HbA} 1 \mathrm{C}$ values between the group that was readmitted and those that were not $((7.63 \%$ vs $7.55 \%), p=0.47)$. The median LOS was higher among the readmitted group (5 vs 4 days) (Table 1 ).

Table 1. HbA1c Testing and Length of Stay by Readmission Status

\begin{tabular}{|l|c|c|c|}
\hline & $\geq 1$ Readmission & No Readmissions & $P$-Value \\
\hline \# of Admissions & $969(12.8)$ & $6592(87.2)$ & \\
\hline \# with HbA1c Tests, $n(\%)$ & $428(44.2)$ & $2971(41.9)$ & 0.008 \\
\hline Average HbA1c, mean (SD) & $7.6(2.1)$ & $7.6(2.2)$ & 0.45 \\
\hline Length of Stay, days, median (min - max) & $5(1-53)$ & $4(1-116)$ & $<0.001$ \\
\hline Length of Stay, days, median (min - max) & $3(1-32)$ & $4(1-116)$ & $<0.001$ \\
\hline Abbreviations: $n=$ number, SD = Standard of Deviation \\
\hline
\end{tabular}

\section{Primary vs. Secondary diagnosis}

Of the total admissions, $453(6 \%)$ had a primary diagnosis of diabetes, and $62(14 \%)$ of those with the primary diagnosis of diabetes were readmitted within 30 days. Similarly, 907 $(12.8 \%)$ of those admissions with a secondary diagnosis of diabetes had at least one 30 -day readmission. In contrast, there was a significant difference between these two groups in the proportion with $\mathrm{HbA} 1 \mathrm{C}$ testing done. More admissions with a primary diagnosis of DM had an $\mathrm{HbA} 1 \mathrm{C}$ done than those with a secondary diagnosis of DM (48\% vs $42 \%, p=0.008)$.

The group with a primary diagnosis of diabetes had a significantly higher $\mathrm{HbA} 1 \mathrm{C}$ (mean $=9.9 \%, S D=3.4$ ) than those with a secondary diagnosis of diabetes (mean=7.5\%, $S D=2.0)(p \leq 0.001)$ (Table 2).

Table 2. Summary of Results by Primary or Secondary Diagnosis of Diabetes

\begin{tabular}{|c|c|c|c|c|}
\hline & Overall & Primary Dx of DM & Secondary Dx of DM & $P$-Value \\
\hline Admissions & 7561 & $453(6.0)$ & $7108(94.0)$ & $\mathrm{N} / \mathrm{A}$ \\
\hline Unique Patients, $n(\%)$ & 5126 & $319(6.2)$ & 4807 (93.8) & $\mathrm{N} / \mathrm{A}$ \\
\hline \# with HbA1c Tests, $n(\%)$ & $3189(42.2)$ & $218(48.1)$ & $2971(41.8)$ & 0.008 \\
\hline Average $\mathrm{HbA} 1 \mathrm{c}$, mean $(S D)$ & $7.6(2.2)$ & $9.9(3.4)$ & $7.5(2.0)$ & $<0.001$ \\
\hline \# Readmissions, $n(\%)$ & & & & 0.58 \\
\hline 0 & $6592(87.2)$ & $391(86.3)$ & $6201(87.2)$ & \\
\hline 1 & $829(11.0)$ & $53(11.7)$ & $776(10.9)$ & \\
\hline 2 & $131(1.7)$ & $9(2.0)$ & $122(1.7)$ & \\
\hline 3 & $9(0.1)$ & 0 & $9(0.1)$ & \\
\hline $\begin{array}{l}\text { Length of Stay, days, median } \\
(\min -\max )\end{array}$ & $4(1-116)$ & $3(1-32)$ & $4(1-116)$ & $<0.001$ \\
\hline
\end{tabular}

\section{Multiple readmissions}

There were 140 initial admissions that had more than one 30-day readmission. More than half $(51 \%)$ of these did not have $\mathrm{HbA} 1 \mathrm{C}$ tests at the initial admission. Among those that did have an $\mathrm{HbA} 1 \mathrm{C}$ test at the initial admission, the mean $\mathrm{HbA} 1 \mathrm{C}$ of $8.1 \%(S D=2.5)$ was significantly higher when compared to those with only 1 readmission (mean $\mathrm{HbA} 1 \mathrm{C}$ of $7.5 \%$, $S D=1.9)(p=0.046)$.

\section{Discussion}

Despite consistent evidence showing that preventive and therapeutic interventions in patients with diabetes significantly improve clinical outcomes, there continues to remain a gap between ideal and actual care. This is likely because these interventions require a multidisciplinary approach with coordinated care amongst various departments given the complex nature of diabetes. ${ }^{6}$ 
$\mathrm{HbA} 1 \mathrm{C}$ is a useful tool to monitor glucose control, and to predict the risk of complications from diabetes. Despite widespread recognition of the utility of $\mathrm{HbA} 1 \mathrm{C}$ as a performance measure of diabetes care, the test is ordered infrequently in the inpatient setting. ${ }^{7,8}$ This was also true in our study where only $44.2 \%$ of patients with readmission and $41.9 \%$ of patients without readmissions had a recent $\mathrm{HbA} 1 \mathrm{C}$ value.

In our study, we found that: 1) $\mathrm{HbA} 1 \mathrm{C}$ levels were measured significantly more in patients with a primary diagnosis of diabetes (48\%) as compared to those with a secondary diagnosis of diabetes $(42 \%), 2$ ) patients with a primary diagnosis of diabetes had a significantly higher HbA1C level ( $\mathrm{HbA} 1 \mathrm{C}$ mean of $9.94 \%)$ than those with a secondary diagnosis of diabetes ( $\mathrm{HbA} 1 \mathrm{C}$ mean of $7.46 \%)$, and 3 ) patients with multiple readmissions had a significantly higher mean $\mathrm{HbA} 1 \mathrm{C}(8.1 \%)$ compared to those with one readmission $(7.5 \%)$. These findings suggest that while a high $\mathrm{HbA} 1 \mathrm{C}$ value may not be a predictor of 30 -day readmission, it may play a role in predicting patients at high risk for multiple readmissions. In a study by Healy et al., the relationship between intensive diabetes education and hospital readmission was analyzed with stepwise backward logistical regression models. Their study showed that formal intensive diabetes education was independently associated with a lower frequency of allcause hospital readmission within 30 days. ${ }^{9}$ These findings are important because readmission is associated with potentially preventable cost and morbidity, ${ }^{4}$ and intensive inpatient diabetes education can decrease readmission rates in medical patients. ${ }^{9}$ As mentioned previously, this stresses the importance of timely recognition of patients with diabetes.

Studies that evaluate readmission risk factors among patients with diabetes can be grouped into those that focus primarily on patients readmitted within 30 days and those that observed readmissions over longer periods of time..$^{10}$ In a review by Rubin in 2015 , studies of at least 2000 patients were tabulated, and the reported factors associated with an increased risk of 30-day readmission included male gender, comorbidity burden, hospital length of stay, government insurance vs. private or no insurance, emergent or urgent vs. elective admission, recent prior hospitalization, and being discharged against medical advice. ${ }^{10}$ There are conflicting data on the association of $\mathrm{HbA} 1 \mathrm{C}$ with 30 -day readmission.

Healy et al. showed that formal diabetes education in hospitalized patients with poor glycemic control ( $\mathrm{HbA} 1 \mathrm{C}>9 \%)$ was associated with decreased frequency of all-cause hospital readmission within 30 days. However, given the narrow $\mathrm{HbA} 1 \mathrm{C}$ range, they were unable to draw a conclusion regarding the effect of $\mathrm{HbA} 1 \mathrm{C}$ on readmission. ${ }^{9}$ In a retrospective cohort study of $\sim 70,000$ inpatients, Strack et al. demonstrated that, regardless of the result, simply measuring the $\mathrm{HbA} 1 \mathrm{C}$ was associated with a decreased risk of 30-day readmission in patients with a primary diagnosis of diabetes, but not those with other primary diagnoses. This may suggest that greater attention to diabetes reflected by measuring the $\mathrm{HbA} 1 \mathrm{C}$ may improve outcomes among patients hospitalized for diabetes. ${ }^{11}$ In contrast, in a retrospective cohort study with 880 patients undergoing coronary artery bypass surgery who were divided into $3 \mathrm{HbA} 1 \mathrm{C}$ groups, Engoren et al. showed that rates of readmission rose from $9 \%$ in patients with $\mathrm{HbA} 1 \mathrm{C}<6.0 \%$, to $15 \%$ in those with $\mathrm{HbA} 1 \mathrm{C}$ between $6.0 \%-7.0 \%$, and to $17 \%$ for those with $\mathrm{HbA} 1 \mathrm{C}>7.0 \% .{ }^{4}$ Liberty et al. investigated the association between $\mathrm{HbA} 1 \mathrm{C}$ levels and outcomes in patients hospitalized in general internal medicine wards. They identified two groups of patients that exhibited different patterns of association between $\mathrm{HbA} 1 \mathrm{C}$ levels and 1 -year mortality. Among patients with no known prior history of diabetes, an $\mathrm{HbA} 1 \mathrm{C}$ level $\geq$ $6.5 \%$ was associated with increased 1 -year mortality risk. In patients with a known history of diabetes, $\mathrm{HbA} 1 \mathrm{C}<6.5 \%$ was associated with an increased 1 -year mortality risk, however, an $\mathrm{HbA} 1 \mathrm{C}>10.0 \%$ showed an elevated risk that was not statistically significant. This suggests that using $\mathrm{HbA} 1 \mathrm{C}$ measurement as a surrogate marker for diabetic care and early identification of possible high-risk patients may assist in implementing measures to improve outcomes and readmission rates among patients hospitalized for diabetes. ${ }^{12}$

In patients with other comorbidities, diabetes is also associated with an increased risk of readmission in patients hospitalized for cardiac surgery, ${ }^{13,14}$ heart failure, ${ }^{15,16}$ acute myocardial infarction, ${ }^{17}$ stroke, ${ }^{18}$ or liver disease. ${ }^{19}$ Considered together, these data suggest that the effect of diabetes on readmission risk may vary by length of follow-up and by primary reason for hospitalization. ${ }^{10}$

A review by Rubin of the existing literature showed that $\mathrm{HbA} 1 \mathrm{C}$ had a varying association with 30-day readmission. Our study adds another dimension to the current literature by 
showing that patients with multiple readmissions within 30 days had a higher $\mathrm{HbA} 1 \mathrm{C}$ when compared to those with one readmission. Additionally, we found that $\mathrm{HbA} 1 \mathrm{C}$ levels are measured more frequently and are higher in value in patients with a primary diagnosis of diabetes.

There are limitations to our study. First, the data were retrieved over a period of 1 year from a single center that practiced tight glycemic control. Dulipsingh et al. carried out an educational intervention at SFHMC for standardization of diabetes care. A hospital-wide multi-disciplinary task force was formed and nursing staff was educated regarding the importance of inpatient glycemic control based on recommendations by this task force. ${ }^{20}$ Hence, while this was possible at SFHMC, similar results may not be observed in hospitals where there is not an already established multi-disciplinary task force in place. Second, as this is a retrospective study, it has some inherent biases and may have some confounding variables that we have not been able to control for. Limitations of using data obtained from the electronic medical record retrospectively include incomplete or missing data, difficulty in verifying documented information, and variability in the documentation among health care personnel. Primary care physicians affiliated with SFHMC use EPIC EMR and we were able to use the HbA1C values completed in the outpatient setting as long as it was completed in our laboratory. We were not able to include results from a laboratory outside the hospital or by providers who do not share our EMR. Third, our modest sample size is a limitation. Additionally, our data indicate that, while the utility of $\mathrm{HbA} 1 \mathrm{C}$ is widely understood in evaluating patients with diabetes, it continues to be ordered infrequently with $<50 \%$ of discharges having a current $\mathrm{HbA} 1 \mathrm{C}$ despite current guideline recommendations to do so. Finally, we looked at data from Oct. $1^{\text {st }}$, 2014-Sept. $30^{\text {th }}, 2015$. Any first admission during that period was indexed as a first admission and any additional admission after that was indexed as a readmission. Some of these patients who were admitted in October may have had prior admissions and may have been readmits, but their October admission was still counted as a first admission.

\section{Conclusion}

In conclusion, obtaining an $\mathrm{HbA} 1 \mathrm{C}$ measurement at time of admission may be a useful tool for predicting patients more likely to have more than one readmission. Due to the inherent limitations of obtaining data retrospectively from electronic medical records we suggest the need for longer term follow-up and further prospective study to evaluate the association between $\mathrm{HbA} 1 \mathrm{C}$ and hospital readmissions. While $\mathrm{HbA} 1 \mathrm{C}$ did not play a role in predicting $30-$ day readmissions, patients with multiple readmissions had higher $\mathrm{HbA} 1 \mathrm{C}$ values. Our analyses also showed that patients with a primary diagnosis of diabetes had significantly higher $\mathrm{HbA} 1 \mathrm{C}$ levels compared to those with a secondary diagnosis of diabetes, stressing the importance of recognizing and diagnosing these patients appropriately in order to provide the appropriate inpatient treatment and thereby prevent further readmissions.

\section{Acknowledgements}

H.B. wrote manuscript, researched data. D.W. contributed to methods, results, reviewed/edited manuscript. L.D. reviewed/edited manuscript, researched data. We would like to acknowledge Brett Shanaman, Senior Decision Support Analyst from Saint Francis Hospital and Medical Center for his help in building the reports on EPIC and providing us with the data reports.

\section{Funding}

This research received no specific grant from any funding agency in the public, commercial, or not-for-profit sectors.

\section{Conflict of Interest Statement:}

The authors declare no conflict of interest

\section{References}

1. Dungan KM. The Effect of Diabetes on Hospital Readmissions. J Diabetes Sci Technol. 2012; 6:1045-1052. 
2. Jencks SF, Williams MV, Coleman EA. Rehospitalizations among patients in the medicare fee-for-service program. NEngl J Med. 2009; 360:1418-1428.

3. American Diabetes Association. Economic costs of diabetes in the US in 2017. Diabetes care. 2018; 41:917.

4. Engoren, M. Schwann TA, Habib RH. Elevated hemoglobin A1c is associated with readmission but not complications. Asian Cardiovasc Thorac Ann. 2014; 22:800-806.

5. American Diabetes Association. 6. Glycemic targets: standards of medical care in diabetes-2018. Diabetes Care. 2018;41: S55-S64.

6. Tricco AC IversNM, GrimshawJM, et al. Effectiveness of quality improvement strategies on the management of diabetes: Asystematic review and meta-analysis.Lancet. 2012; 379:2252-2261.

7. Halkos ME PuskasJD, LattoufOM, et al. Elevated preoperative hemoglobin A1c level is predictive of adverse events after coronary artery bypass surgery. J Thorac Cardiovasc Surg. 2008; 136:631-640.

8. Shah RV, Altman RK, Park MY, et al. Usefulness of hemoglobin A(1c) to predict outcome after cardiac resynchronization therapy in patients with diabetes mellitus and heart failure. Am J Cardio. 2012; 110:683-688.

9. Healy SJ, Black D, Harris C, Lorenz A, Dungan KM. Inpatient diabetes education is associated with less frequent hospital readmission among patients with poor glycemic control. Diabetes Care. 2013; 36:2960-2967.

10. Rubin DJ. Hospital readmission of patients with diabetes. CurrDiab Rep. 2015; 15:17.

11. Strack B, DeShazoJP, Gennings C, et al. Impact of HbA1c measurement on hospital readmission rates: Analysis of 70,000 clinical database patient records. Biomed Res Int. 2014.

12. Liberty IF, Abu Freha N, Baumfeld Y, et al. Prognostic value of glycated hemoglobin for one year mortality following hospitalization in the internal medicine ward. IsrMed Assoc J. 2015; 17:277-281.

13. Ferraris VA, Ferraris SP, Harmon RC, Evans BD. Risk factors for early hospital readmission after cardiac operations. J Thorac Cardiovasc Surg. 2001; 122:278-286.

14. Stewart RD, Campos CT, Jennings B, et al. Predictors of 30-day hospital readmission after coronary artery bypass. Ann Thorac Surg. 2000; 70:169-174.

15. Greenberg BH, Abraham WT, Albert NM, et al. Influence of diabetes on characteristics and outcomes in patients hospitalized with heart failure: A report from the organized program to initiate lifesaving treatment in hospitalized patients with heart failure (OPTIMIZE-HF).Am Heart J.2007; 154:277.e1-277.e8.

16. Keenan PS, Normand SL, Lin Z, et al. An administrative claims measure suitable for profiling hospital performance on the basis of 30-day all-cause readmission rates among patients with heart failure. Circ Cardiovasc Qual Outcomes.2008; 1:29-37.

17. Dunlay SM Weston SA, Killian JM, Bell MR, Jaffe AS, Roger VL. Thirty-day rehospitalizations after acute myocardial infarction: Acohort study. Ann Intern Med. 2012; 157:11-18.

18. Lichtmanj H Leifheit-LimsonEC, Jones SB, et al. Predictors of hospital readmission after stroke: A systematic review. Stroke. 2010; 41:2525-2533.

19. Berman, K Tandra S, Forsseil K. Incidence and Predictors of 30-Day Readmission among Patients Hospitalized forAdvanced Liver Disease. Clin Gastro enterol Hepatol. 2011; 9:254-259.

20. Dulipsingh L, Gaudian B, Spurrier W, et al. Educational intervention along with standardization of diabetes care increased inpatient $\mathrm{HbA}(1 \mathrm{c})$ testing: A pilot program. Conn Med. 2016; 80:231-237. 